\author{
International Journal of Innovative Research in \\ Electrical, Electronics, Instrumentation and Control Engineering
}

Vol. 7, Issue 6, June 2019

\title{
Performance Analysis of PV System For MPPT Using Harmony Search Algorithm
}

\author{
S.Titus ${ }^{1}$, E.P. Sangeetha ${ }^{2}$, R.Ilango ${ }^{3}$ \\ Professor, Department of EEE, K.Ramakrishnan College of Engineering, Trichy, India ${ }^{1,3}$ \\ Assistant Professor, Department of EEE, K.Ramakrishnan College of Engineering, Trichy, India ${ }^{2}$
}

\begin{abstract}
This paper proposes a solar PV connected into the single-phase grid connected system with Harmony Search Algorithm (HSA) for tracking the Global maximum peak point. Boost converter is connected to the grid for energy management system. This proposed scheme provides output with improved power quality under the nonlinear load conditions. Program analysis was implemented to find the peak point under various temperature and radiations. The output of the grid voltage and current can be monitored and compared with inverter output. Depends on the change in voltage and current the duty cycle of the dc-dc converter will change by HS algorithm. This proposed work involves PV panels connected in series to track the maximum peak point. The time varying radiation and temperature are fed as the inputs to the PV panel and the normal harmonic search algorithm is used for Maximum Power tracking. It generates a reference PV voltage and from the reference voltage, an optimum duty cycle $(\beta)$ for the maximum peak is generated. The optimal duty cycle ratio will gives the required output power under nonlinear conditions.
\end{abstract}

Keywords: MPPT, Harmonic search Algorithm, Solar Power, Boost converter

\section{INTRODUCTION}

Nowadays it becomes necessary for alternative power sources such as fuel cells and photovoltaic systems in the distributed power system [1-3]. Many research works are undergone in fuel cell technology, solar energy is accepted as a popular source of non-conventional energy due to its huge number of benefits, particularly low operational cost and less pollution compared to other renewable conditions [4-6]. In Solar Power Generation, the Photo Voltaic (PV) Panels are connected in either series or parallel connection to generate the required voltage and current values. The Maximum Power Point Technique (MPPT)is an algorithm which is used for extracting maximum available power from PV module.The Perturb \& Observe $(\mathrm{P} \& \mathrm{O})$ algorithm and the Incremental Conductance algorithm are the commonly used algorithms for MPPT [7,8]. Solar cells have complex relationship between temperature and total resistance and produces nonlinear loads,MPPT samples the output to obtain maximum power $[9,10]$. The Boost converter is used to maintain the constant voltage level and also used to connect the inverter with the solar panel while the operating voltage levels of solar panel and inverter are normally different [11]. The inverter is used to convert the constant DC voltage to adjustable $\mathrm{AC}$ voltage and helps the system to be connected in the grid [12]. Instead of a two level or three level inverters, the Multi-level inverters are also used for simple grid connection with less total harmonic distortion (THD) with filters or without filters [13-16]

\section{EXISTING METHODOLOGIES}

In existing system different types of MPPT algorithm has been implemented for tracking the maximum power from the solar system.The Perturb and Observe algorithm is a simple technique for maximum power point tracking. It is based on controlling the duty cycle (d) of a dc-dc converter to adjust the PV array terminal voltage at the maximum power point . The power output of the array is monitored every cycle and is compared to its value before each perturbation is made. If a change (either positive or negative) in the duty cycle of the dc-dc converter causes output power to increase, the duty cycle is changed in the same direction. if it causes the output power to decrease, then it is reversed to the opposite direction. The performance of the algorithm is affected by the choice of the perturbation magnitude $(\Delta d)$ of the converter switching duty ratio. Large perturbations will cause large power output fluctuations around the MPP while small perturbations slow down the algorithm. Modifications to this technique are observed and improved while maintaining the basic principle of operation.

Incremental conductance of this algorithm exploits the fact that the slope of the power-voltage curve of a PV array is equal to zero at the maximum power point. The slope is positive in the area to the left of the maximum power point and negative in the area to the right [17]. Many algorithms are used for MPPT Techniques in the grid connected and isolated PV systems [18-24]. 


\section{International Journal of Innovative Research in Electrical, Electronics, Instrumentation and Control Engineering}

Vol. 7, Issue 6, June 2019

\section{PROPOSED WORK}

The harmony memory (HM) stores the feasible vectors, which are all in the feasible space. When a musician changes the pitch, one of three rules were applied: i. Generating any one pitch from his/her memory, i.e. choosing any one value from harmony memory, defined as memory consideration; ii. Generating nearby pitch or equivalent pitch of one pitch in his/her memory, i.e. choosing an adjacent value of one value from harmony memory, defined as pitch adjustments; iii. Generating newly a random pitch from possible sound ranges, i.e. choosing totally random value from the possible value range, defined as randomization. Similarly, when each decision variable chooses one value in the HS algorithm, it can apply one of the abovementioned rules in the entire HS algorithm. If the New Harmony vector is better than the previous worst harmony vector in the harmony memory, then the New Harmony vector will change it. This procedure is repeated until a stopping criterion is satisfied. The NHS algorithm is the improved version of the harmony search by using normal probability distribution factor.

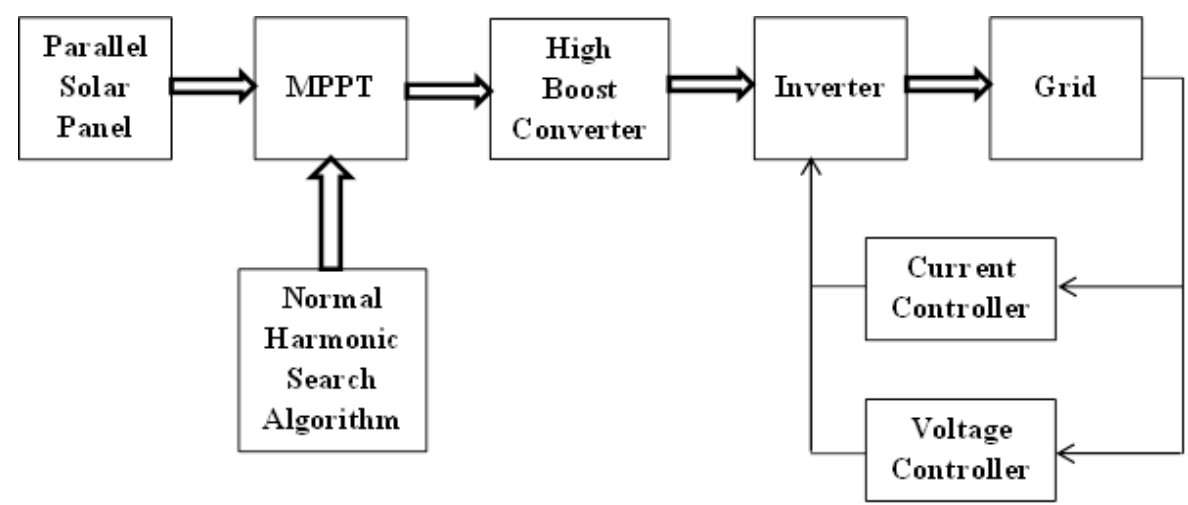

Fig.1.Block diagram of proposed system

The block diagram involves PV panels connected in series to track the maximum peak point. The time varying radiation and temperature are fed as the input to the PV panel.Normal Harmonic Search algorithm is used for optimal MPPT, which generates a reference PV voltage and from the reference voltage, an optimal duty cycle $(\beta)$ is obtained.

\section{SIMULATION RESULTS}

Simulink is a block diagram environment for multi domain simulation and Model-Based Design. It supports systemlevel design, simulation, automatic code generation, and continuous test and verification of embedded systems. Simulink provides a graphical editor, customizable block libraries, and solvers for modeling and simulating dynamic systems. It is integrated with MATLAB $\AA$, enabling you to incorporate MATLAB algorithms into models and export simulation results to MATLAB for further analysis. The simulation results of the PV system using NHS optimization technique are shown in Fig.3. Simulation results depicts that NHS based MPPT algorithm can rapidly and precisely determine the maximum power of each modules and the system accomplished an accurate sense of the maximum power output. Fig.4. shows the ouput of the proposed NHS based system which is maintained constant at different current levels. 
International Journal of Innovative Research in Electrical, Electronics, Instrumentation and Control Engineering

Vol. 7, Issue 6, June 2019

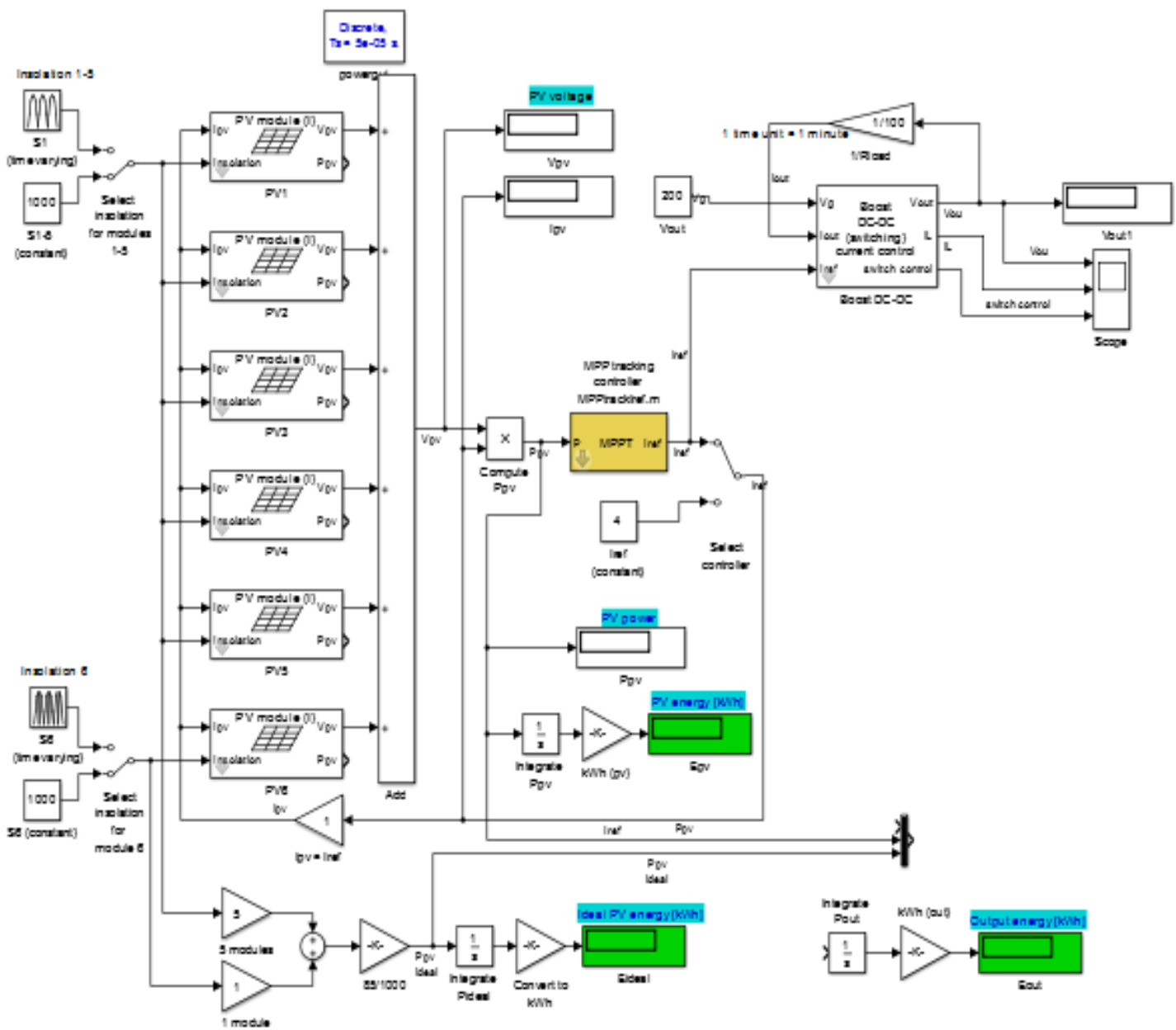

Fig.2.Simulation diagram of proposed system

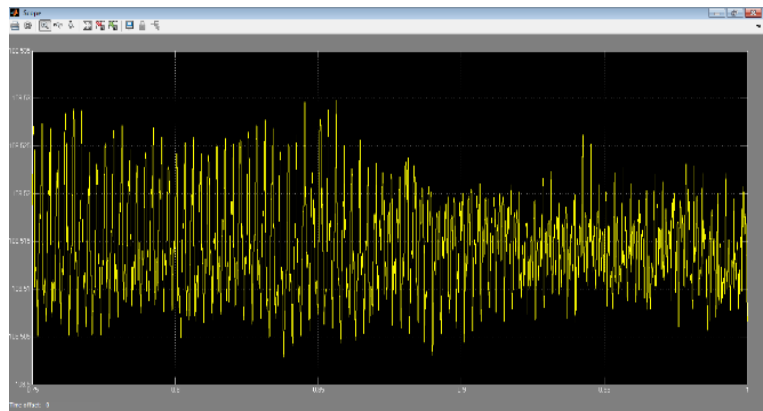

Fig.3.Output of Existing model

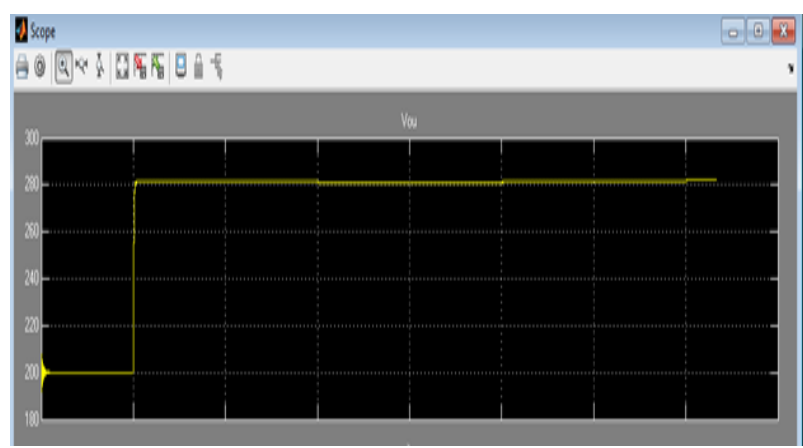

Fig.4.Output of proposed model 
International Journal of Innovative Research in Electrical, Electronics, Instrumentation and Control Engineering

Vol. 7, Issue 6, June 2019

Table.1 Tabulation for varying voltage

\begin{tabular}{|c|c|c|c|c|c|c|}
\hline Current(I) & Duty cycle & $\begin{array}{c}\text { Ripple current } \\
(\mathbf{d i})\end{array}$ & Inductor & $\begin{array}{c}\text { Ripple voltage } \\
(\mathbf{d v})\end{array}$ & capacitor & Resistance \\
\hline 10 & 85 & 12 & 0.01 & 0.50 & 0.34 & 12 \\
\hline 20 & 85 & 24 & 0.08 & 0.50 & 0.68 & 6 \\
\hline 30 & 85 & 36 & 0.05 & 0.50 & 1.02 & 4 \\
\hline 40 & 85 & 48 & 0.04 & 0.50 & 1.36 & 3 \\
\hline 50 & 85 & 60 & 0.003 & 0.50 & 1.70 & 2.4 \\
\hline$s 60$ & 85 & 72 & 0.002 & 0.50 & 2.04 & 2 \\
\hline 70 & 85 & 84 & 0.002 & 0.50 & 2.38 & 1.71 \\
\hline 80 & 85 & 96 & 0.021 & 0.50 & 2.72 & 1.50 \\
\hline 90 & 85 & 108 & 0.019 & 0.50 & 3.06 & 1.33 \\
\hline 100 & 85 & 120 & 0.017 & 0.50 & 3.40 & 1.20 \\
\hline
\end{tabular}

Table 2 Tabulation for varying current

\begin{tabular}{|c|c|c|c|c|c|c|}
\hline Voltage(V) & Duty cycle & $\begin{array}{c}\text { Ripple } \\
\text { current (di) }\end{array}$ & Inductor(L) & $\begin{array}{c}\text { Voltage } \\
\text { Ripple(dv) }\end{array}$ & Capacitor(C) & Resistance \\
\hline 10 & 92.5 & 4.8 & 0.02 & 0.50 & 0.07 & 60 \\
\hline 20 & 85 & 2.4 & 0.83 & 0.50 & 0.06 & 60 \\
\hline 30 & 77.5 & 1.6 & 0.18 & 0.50 & 0.56 & 60 \\
\hline 40 & 70.1 & 1.2 & 0.33 & 0.50 & 0.50 & 60 \\
\hline 50 & 62.5 & 0.96 & 0.50 & 0.50 & 0.04 & 60 \\
\hline 60 & 55.0 & 0.80 & 0.75 & 0.50 & 0.03 & 60 \\
\hline 70 & 47.5 & 0.68 & 1.02 & 0.50 & 0.03 & 60 \\
\hline 80 & 40.0 & 0.60 & 1.33 & 0.50 & 0.23 & 60 \\
\hline 90 & 32.5 & 0.53 & 1.68 & 0.50 & 0.26 & 60 \\
\hline 100 & 25 & 0.48 & 2.08 & 0.50 & 0.02 & 60 \\
\hline 20 & 85 & 2.4 & 0.83 & 0.50 & 0.06 & 60 \\
\hline 30 & 77.5 & 1.6 & 0.18 & 0.50 & 0.56 & 60 \\
\hline 40 & 70.1 & 1.2 & 0.33 & 0.50 & 0.50 & 60 \\
\hline
\end{tabular}

Table 3 Tabulation for varying frequency

\begin{tabular}{|c|c|c|c|c|c|c|}
\hline Frequency(Hz) & $\begin{array}{c}\text { Duty } \\
\text { cycle }\end{array}$ & $\begin{array}{c}\text { Ripple } \\
\text { current(di) }\end{array}$ & $\begin{array}{c}\text { Inductor } \\
(\mathbf{L})\end{array}$ & $\begin{array}{c}\text { Ripple } \\
\text { voltage(dv) }\end{array}$ & Capacitor & Resistance(R) \\
\hline 50 & 85 & 2.40 & 0.83 & 0.50 & 0.68 & 60 \\
\hline 60 & 85 & 2.40 & 0.06 & 0.50 & 0.55 & 60 \\
\hline 70 & 85 & 2.40 & 0.595 & 0.50 & 0.04 & 60 \\
\hline 80 & 85 & 2.40 & 0.521 & 0.50 & 0.04 & 60 \\
\hline 90 & 85 & 2.40 & 0.406 & 0.50 & 0.38 & 60 \\
\hline
\end{tabular}

From the table. 1 it is observed that even though the PV panel output voltage changes the converter output will maintain constant voltage. The NHS algorithm controls the duty cycle ratio of the converter in such a way to maintain constant output voltage. When the system is interfaced with grid, it has to maintain the constant frequency irrespective of the loads. The table 3 shows that, the ripple voltage and currents are not changing with constant duty cycle ratio.

\section{OUTPUT OF PROGRAMMED ANALYSIS}

The Harmony search algorithm was developed for non-linear load conditions and the MATLAB/Simulink Program output is shown in Fig.5. The same algorithm was implemented in the solar PV panel design and the Maximum power points (MPP) were tracked for different solar irradiations. Fig 6.Shows the current and power values with respect to the various voltage conditions which is indirectly means at the different irradiations. 


\section{International Journal of Innovative Research in Electrical, Electronics, Instrumentation and Control Engineering}

Vol. 7, Issue 6, June 2019

Input: Switching Frequency: 60

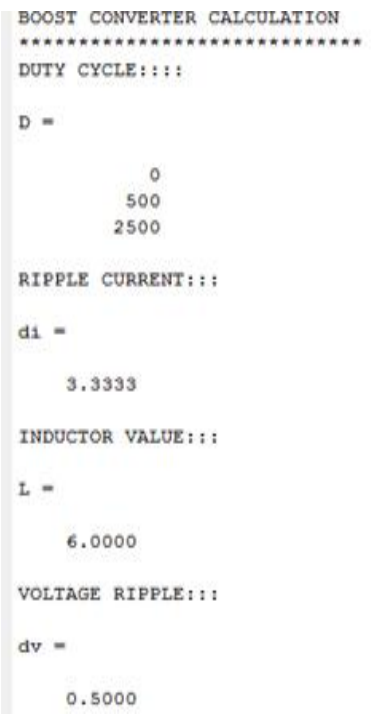

Fig.5.Output for NHS programmed model

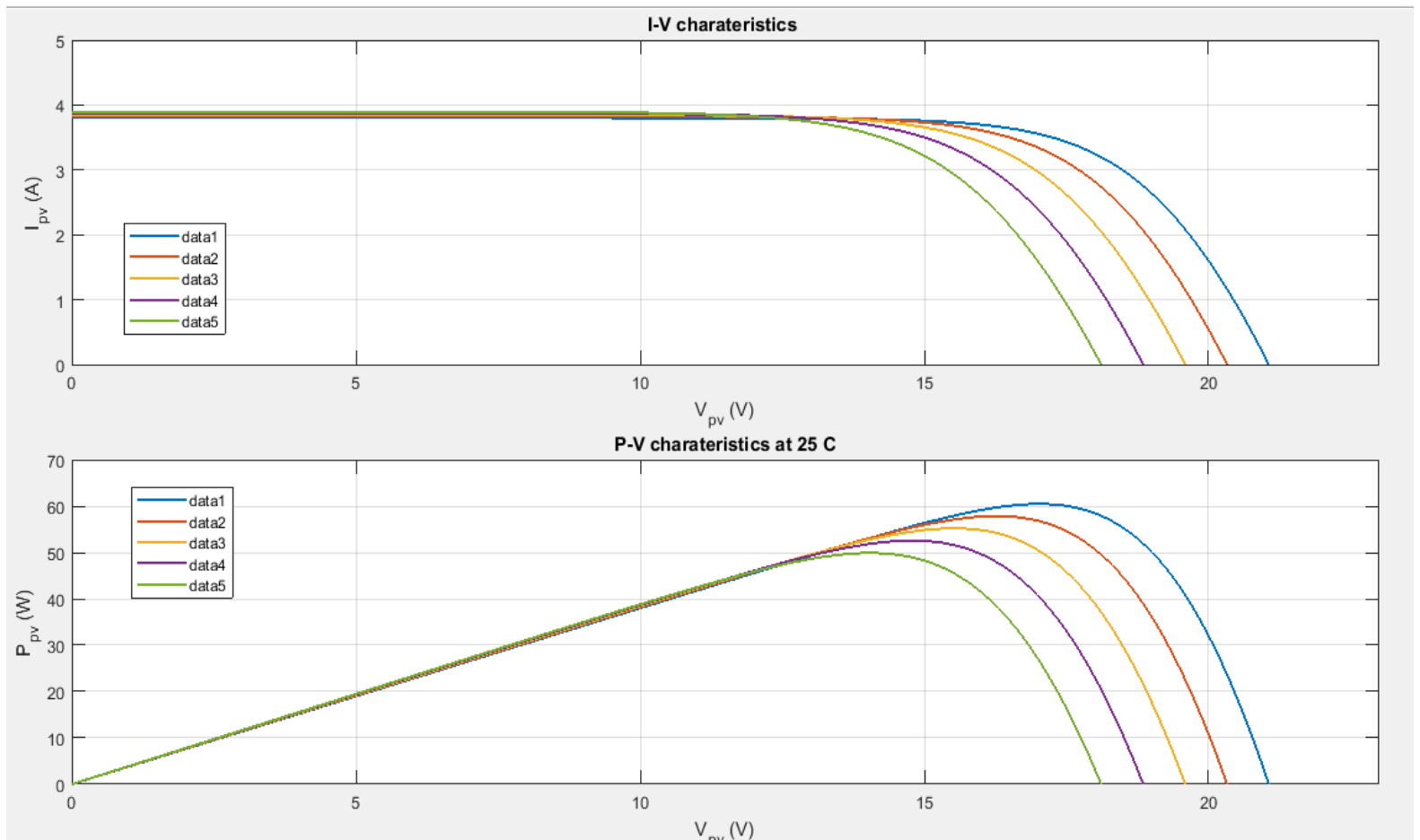

Fig.6.Graph for Maximum peak point

VI. CONCLUSION

The Normal Harmonic Search Algorithm plays major role in Dc-Dc converter to obtain the optimum peak point by accurately varying the duty cycle. This made easily by changing various input voltages, DC ripple voltage does not oscillate, and the output dc ripple voltage is constant. So the PV and IV characteristics achieved the optimum power point with proposed technique. The satisfactory steady-state and dynamic performances of the NHS algorithm are analyzed with variable irradiance and temperature during parallel PV panel operations. The normal harmonic search algorithm has been improved with the reduction of operating frequency and with high search efficiency of various duty cycle values the maximum power point (MPP) is achieved. 


\title{
International Journal of Innovative Research in Electrical, Electronics, Instrumentation and Control Engineering
}

\author{
Vol. 7, Issue 6, June 2019
}

\section{REFERENCES}

[1]. M.T.A. Khan, G.Norris, R.Chattopadhyay, I. Husain \& S. Bhattacharya, "Autoinspection and Permitting With a PV Utility Interface (PUI) for Residential Plug-and-Play Solar Photovoltaic Unit," IEEE Trans. Industry Appl., vol. 53, no. 2, pp. 1337-1346, March-April 2017.

[2]. X.Guo, “A Novel CH5 Inverter for Single-Phase Transformerless Photovoltaic System Applications,” IEEE Trans. Circuits and Systems II: Express Briefs, vol. 64, no. 10, pp. 1197-1201, Oct. 2017

[3]. X. Guo, B. Wei, T. Zhu, Z. Lu, L. Tan, X. Sun, and C. Zhang "Leakage Current Suppression of Three-Phase Flying Capacitor PV Inverter With New Carrier Modulation and Logic Function,” IEEE Trans. Power Electronics, vol. 33, no. 3, pp. 2127-2135, March 2018

[4]. G.A. Sangwongwanich, Y. Yang, F. Blaabjerg and H. Wang, "Benchmarking of Constant Power Generation Strategies for Single-Phase Grid-Connected Photovoltaic Systems," IEEE Trans. Industry Applications, 2017, (Early Access Articles). Eason, B. Noble, and I. N. Sneddon, "On certain integrals of Lipschitz-Hankel type involving products of Bessel functions," Phil. Trans. Roy. Soc. London, vol. A247, pp. 529-551, April 1955

[5]. R. Kumar and B. Singh, "BLDC Motor-Driven Solar PV Array-Fed Water Pumping System Employing Zeta Converter," IEEE Trans. Industry Applications, vol. 52, no. 3, pp. 2315-2322, May-June 2016.

[6]. A. El Khateb, N. A. Rahim, J. Selvaraj and M. N. Uddin, "Fuzzy-Logic-Controller-Based SEPIC Converter for Maximum Power Point Tracking," IEEE Trans. Industry Appl., vol.50, no 4, pp.2349-2358, July 2014

[7]. Ilango. R, Venkatesa Vimal Chand. M.R.V (2015) 'Selective Harmonic Elimination-PWM Technique in a Single Phase Hybrid Cascaded Multilevel Inverter using Bee Algorithm', International Journal of Innovative Research in Engineering Science and Technology, ISSN no. 2320 - 981X, vol. III Issue 04, pp. 13-18.

[8]. N. Kumar, I. Hussain, B. Singh and B. K. Panigrahi, "Maximum Power Peak Detection of Partially Shaded PV Panel by Using Intelligent Monkey King Evolution Algorithm,” IEEE Trans. Industry Applications, vol. 53, no. 6, pp. 5734-5743, Nov.-Dec. 2017

[9]. K. Sundareswaran, S. Peddapati and S. Palani, "MPPT of PV systems under partial shaded conditions through a colony of flashing fireflies," IEEE Trans. Energy Conversion, vol. 29, no. 2, pp. 463-472, June 2014.

[10]. A. El Khateb, N. A. Rahim, J. Selvaraj and M. N. Uddin, "Fuzzy-LogicController-Based SEPIC Converter for Maximum Power Point Tracking,” IEEE Trans. Industry Appl., vol.50, no 4, pp.2349-2358, July 2014.

[11]. Titus.S \& Rajalakshmi.S "FITF-PDM: Unified controller design for non-isolated bidirectional DC-DC converter" International Transactions on Electrical Energy Systems (John Wiley \& Sons), Vol.28, Issue.3, pp.1-19, December 2017.

[12]. A. Sangwongwanich, Y. Yang, F. Blaabjerg and D. Sera, "Delta Power Control Strategy for Multistring Grid-Connected PV Inverters," IEEE Trans. Industry Appl., vol. 53, no. 4, pp. 3862-3870, July-Aug. 2017.

[13]. S.Titusand S.Edwin Jose "An zig-zag concated double rung h-bridges based multilevel voltage source inverter structure" in Journal of Electrical Engineering, Vol. 18, No. 1, pp. 01-08, March 2018.

[14]. M.Jayalakshmi, G Asha and K Keerthana, Control of Single Phase Z-Source Inverter Fed Induction Motor Using Simple Boost Controller, International Journal of Emerging Trends in Electrical and Electronics, vol.10,issue 10,pp.44-48,2014.

[15]. U. M. Choi, F. Blaabjerg and K. B. Lee, "Control Strategy of Two Capacitor Voltages for Separate MPPTs in Photovoltaic Systems Using Neutral-PointClamped Inverters,” IEEE Trans. Industry Applications, vol. 51, no. 4, pp. 3295-3303, July-Aug. 2015.

[16]. M. Hojabri and M. Hojabri "Design, Application and Comparison Of Passive Filters For Three-Phase Grid-Connected Renewable Energy Systems," ARPN Journal of Engineering and Applied Sciences, vol. 10, no. 22, pp. 10691-10697, Dec 2015.

[17]. Dhayalini, K.;" A novel electrical and mechanical MPPT for Solar Photovoltaic System at any climatic condition and sudden changes in the irradiance" International Journal of Advancement in Chemistry,vol.12,no. 18,pp. 5070-5079, March2016

[18]. Revathi, A Jeyalakshmi, C Muruganantham, T "Perceptual Features based Rapid and Robust Language Identification System for Various Indian Classical Languages", In: Hemanth D., Smys S. (eds) Computational Vision and Bio Inspired Computing. Springer Lecture Notes in Computational Vision and Biomechanics book series (LNCVB), vol. 28, pp.291-305, 2018.

[19]. M. Jiang, W. Liu and Y. Li, “Adaptive Beamforming for Vector-Sensor Arrays Based on a Reweighted Zero-Attracting Quaternion-Valued LMS Algorithm," IEEE Trans. Circuits and Systems II: Express Briefs, vol. 63, no. 3, pp. 274-278, March 2016

[20]. L. R. Chen, C. H. Tsai, Y. L. Lin and Y. S. Lai, "A biological swarm chasing algorithm for tracking the PV maximum power point," IEEE Trans. Energy Conversion, vol. 25, no. 2, pp. 484-493, June 2010

[21]. N.Mahmud, A.Zahedi \& A. Mahmud, “A Cooperative Operation of Novel PV Inverter Control Scheme \& Storage Energy Management System Based on ANFIS for Voltage Regulation of Grid-Tied PV System,” IEEE Trans. Industrial Informatics, vol.13, no.5, pp.2657-2668, Oct. 2017.

[22]. B.Kiranbala, S Audithan, Wavelet and curvelet analysis for the classification of microclacifiaction using mammogram images, Proceedings of Second International Conference on Current Trends in Engineering and Technology-ICCTET 2014, pp.517-521

[23]. Revathi, A Jeyalakshmi, C Muruganantham, T "Perceptual Features based Rapid and Robust Language Identification System for Various Indian Classical Languages", In: Hemanth D., Smys S. (eds) Computational Vision and Bio Inspired Computing. Springer Lecture Notes in Computational Vision and Biomechanics book series (LNCVB), vol. 28, pp.291-305, 2018.

[24]. A. Sangwongwanich, Y. Yang, F. Blaabjerg and D. Sera, "Delta Power Control Strategy for Multistring Grid-Connected PV Inverters," IEEE Trans. Industry Appl., vol. 53, no. 4, pp. 3862-3870, July-Aug. 2017 